\title{
Quality of family planning programme in India: A review of public and private sector
}

Dileep V. Mavalankar

Follow this and additional works at: https://knowledgecommons.popcouncil.org/departments_sbsr-rh

Part of the Demography, Population, and Ecology Commons, International Public Health Commons, Maternal and Child Health Commons, and the Quality Improvement Commons How does access to this work benefit you? Let us know!

\section{Recommended Citation}

Mavalankar, Dileep V. 1996. "Quality of family planning programme in India: A review of public and private sector," Special Report. New Delhi: Population Council. 


\title{
QUALITY OF FAMILY PLANNING PROGRAMME IN INDIA: A REVIEW OF PUBLIC AND PRIVATE SECTOR
}

\author{
Dileep V. Mavalankar
}

Paper prepared for a volume on "Population Dynamics of India - Current Status and Future Directions". Edited by M.E. Khan and John W. Townsend, to be published soon.

The Population Council, India 1996 


\section{Quality of Family Planning Programme in India:}

A review of Public and Private sector

By: Dr. Dileep V. Mavalankar, Asst. Prof. Public Systems Group, Indian Institute of Management, Ahmedabad

JAN. 1996

This paper was commissioned by the Population Council, New Delhi. 


\begin{abstract}
Increasing attention has been paid to quality of care in family planning during the last few years. Seminal work by Judith Bruce provided framework for quality of care in family planning. Internationally there has been several initiatives to strengthen the quality of care in family planning programme in developing world. This paper tries to review quality of family planning programme in India in the public and private sectors. The paper follows Judith Burce's framework to examine quality of care under each of the six elements namely Choice of Methods; Information Given to Clients; Technical Competence; Interpersonal Relations; Continuity of Care and Follow Up; and Appropriate Constellation of Services. Overall the review finds that not much attention has been paid to quality of care and hence the level of quality is quite low. The evidence and observations indicate that quality of care may be slightly better in the non-governmental sector. This could be due to various reasons including its small size and better supervision. The review also points the fact that in many areas adequate information is not available to assess the quality of care, especially in private sector. Overall substantial efforts are needed to improve the quality of care in family planning in India.

The paper also discusses reasons for why the quality of care is poor? and suggestions are offered for improving each dimension of quality of care using the Burce's framework. Finally, managerial implications of quality improvement are discussed. As Government of India is actively considering to revise family planning programme strategy and adopting reproductive health approach, it may be an opportune time to improve quality of care in the family welfare programme.
\end{abstract}




\section{List of Abbreviations}

$\begin{array}{ll}\text { ACS } & \text { Appropriate constellation of services } \\ \text { ANC } & \text { Antenatal care } \\ \text { AVSC } & \text { Association for Voluntary Surgical Contraception } \\ \text { BP } & \text { Blood pressure } \\ \text { CORT } & \text { Centre of operations research and training } \\ \text { ESIS } & \text { Employees state insurance scheme } \\ \text { FP } & \text { Family planning } \\ \text { FPAI } & \text { Family palnning association of India } \\ \text { GSCPT } & \text { Gujarat State Crime Prevention Trust } \\ \text { HRRC } & \text { Human reproduction research centre } \\ \text { ICMR } & \text { Indian council of medical research } \\ \text { ICOMP } & \text { International council on management of population } \\ \text { IIM } & \text { Indian institute of management } \\ \text { IIPS } & \text { Indian institute of population studies } \\ \text { IUD } & \text { Intrauterine divice } \\ \text { MCH } & \text { Maternal and child health } \\ \text { MTP } & \text { Medical termination of pregnancy } \\ \text { NFHS } & \text { National Family Health Survey } \\ \text { NGO } & \text { Non-governmental oraganization } \\ \text { OC } & \text { Oral contraceptives } \\ \text { ORG } & \text { Operations research group } \\ \text { PHC } & \text { Primary Health care / centre } \\ \text { SAIL } & \text { Steel authority of India } \\ \text { SC } & \text { Subcentre } \\ \text { TBA } & \text { Traditional birth attendent } \\ \text { UNFPA } & \text { United Nations Fund for Population Activities } \\ & \end{array}$




\title{
Quality of Family Planning Programme in India:
}

\section{A review of Public and Private sector}

\author{
Dileep V. Mavalankar*
}

Lately more and more attention has been paid to quality of family planning (FP) programmes internationally, even though good family planning programmes always had implicit focus on good quality of care. Framework for quality of care provided by Judith Bruce and work by Anrudh Jain ${ }^{2}$ has helped to explicitly focus attention of international family planning organizations on the issue of quality which had been neglected for quite some time in population programmes. Within last few years several international agencies and research organizations have started working on measuring and improving quality of care in FP programmes ${ }^{3,4,5}$. India has the oldest FP programme and yet very few reviews have been made of its quality. This paper reviews the quality of care offered by the government FP programme and the private sector in India. Reasons for the inadequate quality are discussed and efforts needed to improve quality are outlined at the end of the paper.

1Judith Bruce. Fundamental elements of the quality of care: A simple framework. Studies in Family Planning, 1990, 21(2):61-91.

2 Anrudh Jain Ed. Managing quality of care in population programmes. Kumarian press 1992.

3Karen Hardee, Brian J. Gould. A process for quality improvement in family planning services. International Family Planning perspectives 1993, 19(4):147-152.

4i) Pamela Lynam, Leslie McNeil Rabinovitz, and Mofoluke Shobowale., The Use of Self-Assessment in Improving the Quality of Family Planning Clinic Operations: The Experience with COPE in Africa, AVSC Working Paper No.2. December 1992.

5Innovative Approaches to Population Programme Management Innovations: Quality of Care, Vol.1, 1994, ICOMP, Malaysia.

\footnotetext{
* Asst. Prof. Public Systems Group, Indian Institute of Management, Ahmedabad
} 
India claims the credit of having started the first government sponsored FP programme which started in 1952 and privately supported FP work dates back to $1923^{6}$. India with its huge population of about 900 million and tremendous cultural diversity is served by a mixed health and family planning systems. It has large and growing government sector as well as private health and FP services. Table 1 shows the typology of providers of FP services in India. It is clear that the system of FP services is mixed and complex with plethora of agencies and organizations playing a part in provision of PF services.

\section{Table 1}

\section{Agencies providing FP services in India}

\begin{tabular}{|c|c|}
\hline $\begin{array}{l}\quad \text { Government Agencies } \\
\text { Central Government' health } \\
\text { department } \\
\text { Central Government Health Services } \\
\text { State Government's Health } \\
\text { Department } \\
\text { District Health Office } \\
\text { City (Municipal) Health Department }\end{array}$ & $\begin{array}{l}\quad \text { Non-Governmental Organizations } \\
\text { Non Profit NGOs - Family Planning Association } \\
\text { of India, Indian Medical Association, Women's } \\
\text { Organizations, Pariwar Sewa Sansthan (Marie } \\
\text { Stopes clinics) } \\
\text { Private Hospitals } \\
\text { Industry and Corporate Sector - Tata Steel, } \\
\text { Godrej, L\&T }\end{array}$ \\
\hline $\begin{array}{l}\qquad \text { Semi-government } \\
\text { Organized Sector } \\
\text { ESIS, Railways, Defence } \\
\text { Government Enterprises, SAIL etc. } \\
\text { Social Marketing Programme }\end{array}$ & $\begin{array}{l}\text { Solo Private Practitioners } \\
\text { Private Practitioners - western system and } \\
\text { indigenous systems, Specialists and GPs. }\end{array}$ \\
\hline
\end{tabular}

The contribution of each of the above agencies in family planning effort is difficult to assess. Government estimates that NGOs provide about $9 \%$ of total FP Services. The corporate sector covers about $11 \%$ of the workforce in the country and some of which have their own FP programme. There was no good estimate of FP services provided by private practitioners but their role seems small. Recent data from NFHS give in the table 2 shows that government is the major provider of sterilization which is the main method used in India. While private sector is important in provision of spacing methods. Over all it seems that government FP

6JP Gupta, NK Sinha, A. Bardhan. Evolution of family welfare programme in India. Vol. 1. National Institute of Health and Family Welfare, New Delhi. 1992. P. 13-20.

* Asst. Prof. Public Systems Group, Indian Institute of Management, Ahmedabad 
programme is the major contributor to FP services in the country. There are many studies and surveys of the government FP programme while research on NGO run FP programmes is substantially less and not easily accessible. Due to both these reasons most of this paper is devoted to analysis of the government run FP programme with comparison with private sector whenever data was available. 
Table 2:

Source of Contraceptive Methods Used: NFHS Data, All India 1992-93

\begin{tabular}{||l|c|c|c|c|c|c||}
\hline Source of Supply & Pill & IUD & Condom & $\begin{array}{l}\text { Female } \\
\text { Sterilizatio } \\
\mathrm{n}\end{array}$ & $\begin{array}{l}\text { Male } \\
\text { Sterilizatio } \\
\mathrm{n}\end{array}$ & $\begin{array}{l}\text { All Modern } \\
\text { Methods }\end{array}$ \\
\hline Public Sector & 31.0 & 62.6 & 15.2 & 86.1 & 93.4 & 79.0 \\
\hline $\begin{array}{l}\text { Private Medical } \\
\text { Sector }\end{array}$ & 41.5 & 35.8 & 20.3 & 13.3 & 4.3 & 15.0 \\
\hline $\begin{array}{l}\text { Other Sources } \\
\text { (includes shops, } \\
\text { relatives sources) }\end{array}$ & 27.4 & 1.6 & $64.5^{\star}$ & 0.6 & 2.3 & 6.0 \\
\hline
\end{tabular}

* Includes $39 \%$ who reported shop as source and $21 \%$ who reported husband as the source of condoms.

The table shows that the public sector, including government/municipal hospitals, Primary Health Centres and other government health facilities, supply methods to 79 per cent of all modern method users. The private medical sector, including private hospitals or clinics, private doctors and pharmacies/drugstores, supply 15 percent of users. Another 5 per cent of users obtain their methods from other sources, such as shops, friends and relatives.

Literature on actual assessment of quality of care in India is very limited as it is so internationally. This paper on quality of care in FP is based on review of published and unpublished literature on FP projects in India, observations and research in the field primarily in Gujarat, some in Orissa and Tamil Nadu and discussions with professionals in the FP field in India. Hence many of the observations could be non-representative of the whole country. In fact quality of care varies a great deal and is very locale specific. But general observations and problems seem surprisingly common across states, areas and programmes. This may be because FP is a national programme.

I have used the framework proposed by Judith Bruce for organizing this review of quality of care. Each of the six elements of quality of care are examined in government and nongovernmental programmes to see what is the current status of quality. Then I discuss possible reasons for poor quality of care in India and finally some suggestions for improvement are presented. The framework on quality of care has six elements on which quality is measured. They are choice of methods, information given to clients, technical competence of providers, interpersonal relations between clients and providers, follow up and continuity mechanisms, and appropriate constellation of services. I take these one by one and examine the evidence to assess quality on each dimension within the government and non-governmental sectors. 


\section{Choice of Methods:}

Choice of methods is important aspect of quality of care because "one size does not fit all". People have different needs in different phases of their life cycle and people's preferences vary based on several socio-cultural factors. The government FP programme is supposed to be providing "cafeteria approach" with multiple choices of contraceptives. Most official documents claim that the government programme offers wide choice of methods. But in practice the choice is constrained by various factors. Firstly the method specific target oriented approach enforced from the central government means that each peripheral worker must recruit a specified number of clients for each of the methods irrespective of the area, the culture or people's preferences. Thus the method specific targets act counter to free choice. The worker tends to consciously or subconsciously guide the clients to use the method for which worker's target achievement is deficient. The pressure to achieve targets by March end is reflected in acceptance figures which rise from April to March in an annual cycle. Usually the performance for last quarter (January to March) of the financial year is double as compared to the first quarter (April to June) ${ }^{7}$.

7Family Planning: Wages of "Target Orientation". Economic and Political Weekly, July 1988. P.1449-50. Even recent data from Maharashtra shows that number of sterilizations in the last quarter are more than double the number in first quarter of the financial year. Data from Gujarat also shows same trend. 
Second factor which constrains the choice is singular focus of the programme managers on sterilization. Before mid eighties the FP programme was mainly sterilization oriented with only very small contribution from spacing methods. Since that time the spacing method targets have been substantially increased and the target achievement for spacing methods has also gone up. But in the field one still finds much more importance attached to sterilization in monitoring and evaluations for performance of the health department staff. Sterilization achievement also counts in the evaluation of general administrators (IAS officers) in charge of the district administration. Most officers in administration recognize the ease with which spacing method data can be manipulated, hence they give more importance to sterilization performance for evaluation. The punitive pressure to achieve sterilization targets force workers to direct their attention solely to getting sterilization cases. Both the above factors are well recognized shortcoming of the Indian government FP programme ${ }^{8}$. The choice also gets limited because health workers and doctors do not explain all the methods to the clients. A study in 64 villages of Samastipur district of Bihar state showed that in only $35 \%$ of interaction with the workers for FP did the workers inform the client about all the available methods of contraception. Our observation in rural and urban areas of Gujarat also confirms this impression. This means that even if 3-4 methods are potentially available at the health centre the choice is made by the provider rather than the client. Providers often have preconceived notion that illiterate and poor clients will not understand the information and can not make the choice. Hence they make the choice for the clients or offer them no choice. The social distance between the providers and clients may also be minimizing the communication between them. But it is not true for rural areas as workers are from the same village.

The third factor that limits choice is the lack of access and availability of the methods at various centres. Even though all PHC and sub-centres are supposed to provide all spacing methods several studies have shown that the required supplies, equipment and skills are lacking at many places. For example a large study done in 19 states and union territories by ICMR in 1987-89 showed that in most of the PHCs IUDs, OCs and condoms were available but of the 598 sub-centres studied more than half did not have IUDs and more than a quarter did not have OCs and condoms ${ }^{9}$. The same study observed that in only $23 \%$ of the 398 PHCs observed the operation theatre was properly equipped and maintained. Concurrent evaluation of the FP programme showed that IUDs were available in $79 \%$ of the PHCs while OCs and Condoms were available only in $58 \%$ and $68 \%$ of the $347 \mathrm{PHCs}$ studied respectively ${ }^{10}$. Many SC do not have even basic equipments such as BP instrument which is crucial for follow up of OC users. The problems of irregular supply keeps plaguing the FP programme and limits the access and choice of contraception.

Fourth factor that limits the choice in government programme is the fact that government has been allowing only one type of condoms, one type of pills and one type of IUD. The government condoms were non-lubricated hence would not be preferred by more

${ }_{8}$ Shanti Conly, Sharon Camp. India's family planning challenge: From Rhetoric to Action. Country Study Series no. 2. The population crisis committee, 1992. Washington DC.

9 Evaluation of quality of family welfare services at primary health centre level. An ICMR task force study. Indian Council of Medical Research, 1991. New Delhi. P. 15.

10 As cited in: M.E.Khan, Bella Patel. Review of family planning in Uttar Pradesh: A Synthesis. Operations Research Working paper no. 3, Population Council, India 1993. P.40 Table 3.7. 
discriminating clients. The OC pill in government programme are low dose Oestrogen and Progesterone combination which are unsuitable for lactating women. Progesterone only pill has not been introduced in the programme. In a country where most women breast feed for prolonged periods this limits the choice substantially. Lactation Amenorrhoea Method and other natural family planning methods are also not incorporated in the national FP programme even though more than $10 \%$ of contraceptive use is due to traditional methods. Their knowledge about these methods is often incorrect and incomplete as shown by our studies.

Fifth factor that has limited the choice of methods in India is the fact that some highly vocal urban feminist groups have consistently opposed the introduction of new hormonal methods like injectable and implants. Prolonged court battles have kept these methods out of India for several years. The questions of safety of the new methods become more acute in the context of poor quality of care which the programme offers.

The social marketing programme for condoms started in 1969 with collaboration of government and private retail marketing companies. It has helped to expand the access and choice available to the clients in urban and rural area. But still the access to condoms is limited in rural areas especially in smaller villages. Data show that even now only $24 \%$ of villages have at least one retail outlet which sells condoms. In smaller villages with population less than 1000 this proportion is only $15 \%{ }^{11}$. With discontinuation of village health workers scheme this potential source of condoms at village level has disappeared.

\section{The NGO Sector}

Non-governmental sector is varied in ownership, funding and management. The overall choice of contraceptives they can offer is similar to government set up and depends on several factors. But generally the NGO sector is under less pressure of method specific targets and is less obsessed with monitoring sterilization targets hence they may be offering better choice to clients. Due to flexibility offered by NGO management they can ensure more regular supply of contraceptives to their clients even if they are getting their supplies from government as they can buy supplies from local market if government supplies are exhausted. For example, GSCPT, an urban NGO from Ahmedabad bought supplies from local market when government supplies were inadequate, while in government PHCs the programme may have suffered $^{12}$. Not many NGOs have done any special efforts to widen the choice of contraceptives. FPAI programme in Varanasi and Janmangal project in Rajasthan have been offering community based delivery of various methods which increases the availability and choice of methods.

11Narsiman R and Khan ME. Social marketing of condoms in India. A trend analysis for the period of 198191. Paper presented at the national workshop on 'Alternative strategies for promoting spacing methods' April 1992, New Delhi. As cited in Khan ME, Patel Bella. OR working paper 3, 1993. Population council, India.

12 Gujarat State Crime Prevention Trust. Case study of FP IEC and services delivery project prepared by IIM Ahmedabad, 1993.

Tata Steel. Report of the Family welfare activities, Jamshedpur. 
According to the recent strategy to introduce injectable and implants through open market may mean that private practitioners can offer more choice to their clients who can afford to buy these contraceptives from the market and can afford private doctors' fees.

Overall all the contraceptive prevalence data in India shows that $85 \%$ of the couple protection is because of sterilization alone, with very little use of temporary methods. This may be a reflection of limited effective choice available to Indian couples. On this dimension of choice of quality of FP efforts need improvement.

\section{Information given to clients:}

To make choice of the clients effective and informed complete and correct information is critical. Information also helps in improving acceptance of methods and their continued use. Information has several levels viz. information about possibilities of controlling fertility, information on existence of various methods, information on advantages and disadvantages including side-effects and complications of the methods, information on how to use the method, information on where to get the method, the cost etc. information on what to do if the method is not suitable or causes problems.

Government FP programme's record on giving information must be seen to be believed. Unfortunately there are no good studies of the interaction of the health workers and the clients in India. But surveys and small scale qualitative studies throw some light on the information giving aspect of the programme. The government has been able to inform almost all couples in India about existence of sterilization. The third national survey on FP done by ORG in 1988 shows that about $89 \%$ and $95 \%$ of couples knew of vasectomy and tubectomy respectively. But substantial proportion of couples did not know about the existence of various temporary methods. This survey showed that only $55 \%$ knew of IUD, $60 \%$ knew of pills and $66 \%$ knew of condom. "Some what correct" knowledge of the method was much lower. Only half the couples had some what correct knowledge of tubectomy and condoms, while only about one third knew about IUD, OC and vasectomy somewhat correctly ${ }^{13}$. The recent NFH Survey showed that knowledge of spacing methods are still incomplete. This is in spite of a contraceptive prevalence of $40 \%$ by modern methods and in a programme which started in 1952. Table three summarises the data from the ORG and NFHS.

Data on what information each client actually receives is difficult to get. But small studies show that information provided to the clients is limited. Study from Samastipur district of Bihar showed that out of women who were given information about FP methods only one third received information about all methods. And only one third of the women were given

reasonably complete information about the methods ${ }^{14}$. Our field observations from rural and

13 ORG 1990, Family Planning Practices in India: Third all India survey. Vol II, Ministry of Health and Family welfare. Operations Research Group, Baroda. P. 48-53.

14 M E Khan, Rudranath Prasad, Bella Patel, Ram Bachan Ram. Quality of care in family welfare programme from user's perspective. Paper presented at seminar on 'Quality of care issues in health and family welfare' Organized by Gujarat Institute of Development Research, Ahmedabad, April 1994. 
urban areas of Gujarat show the same picture of scanty and incomplete information given to the clients. This leads to various misconceptions in the minds of the clients and the non-users that hamper the programme efforts. For example our study showed that $40 \%$ of the women in three PHCs surveyed in north Gujarat believed that laparoscopic sterilization causes "burns in the abdomen" which leads to several complications later on.

\section{Table 3}

\section{Percent of Couples Knowing FP Methods}

\begin{tabular}{|c|c|c|c|c|c|c|c|}
\hline Survey & $\begin{array}{l}\text { Any } \\
\text { Modern } \\
\text { Method }\end{array}$ & $\begin{array}{l}\text { Any } \\
\text { Spacing } \\
\text { method }\end{array}$ & $\begin{array}{l}\text { Female } \\
\text { Sterilizati } \\
\text { on }\end{array}$ & $\begin{array}{l}\text { Male } \\
\text { Steriliz } \\
\text { ation } \\
\end{array}$ & IUD & $\begin{array}{l}\text { Oral } \\
\text { pills }\end{array}$ & $\begin{array}{l}\text { Condo } \\
\mathrm{ms}\end{array}$ \\
\hline ORG Survey 1988 & & & & & & & \\
\hline 1. Some Knowledge. & & & 95 & 89 & 55 & 60 & 66 \\
\hline $\begin{array}{l}\text { 2. Some what correct } \\
\text { Knowledge. }\end{array}$ & & & 50 & 33 & 33 & 33 & 50 \\
\hline NFHS 1992-93 & & & & & & & \\
\hline $\begin{array}{l}\text { 1. Knowing the method } \\
\text { with Probe }\end{array}$ & 96 & 76 & 95 & 85 & 61 & 66 & 58 \\
\hline 2. Know source of method & 89 & 64 & 87 & 76 & 51 & 54 & 48 \\
\hline
\end{tabular}

Several such misconceptions were reported by the women in that area about spacing methods as well ${ }^{15}$. Our observations in clinics run by city municipal authorities show that workers give very limited information to the clients - usually in 3-4 sentences about the method. Side effects and problems are never discussed, clients are not encouraged to ask questions. The workers assume that the clients know about the method. This absence of information communication is due to lack of information with the workers and even at times with doctors, and secondly due to shyness to discuss such private and sensitive matters. The situation seems to be so because in the basic training of the workers and doctors information giving or counselling is not included or emphasised. And this deficiency is not made up in any pre or in-service training programmes. The workers do not have appropriate audio-visual materials and models for proper communication with the clients. It is also equally true that what ever materials they have been provided are usually not used and keep lying in one corner of the clinic gathering dust. This is so because the supervisors almost never insist that the workers must properly provide information to the clients. Informally the system believes in getting the client ready for operation by hook or crook. And the incentives and targets for sterilization continue to perpetuate this system. Providing information requires time and patience. The government staff is many a times saddled with so much of record keeping and

15 D V Mavalankar, JK Satia, B Sharma. Strengthening Primary Health Care Services: Insights from qualitative research in West India. Indian Institute of Management Working Paper no. 1078, January 1993. 
sundry work that they may not have the time to talk with the clients. Lack of time is also because many doctors and other staff do not stay at the headquarters and commute from their homes which means that time at work is cut down substantially. The IEC activities are also too few and far between, messages are very general and vague at community level. Mass media efforts are substantial through TV and radio.

Thus over all information provision in government sector is weak and does not receive any priority.

\section{The NGO Sector}

Within NGO sector provision of information varies. There are centres which may not be very different than government system with little information being given. While there are other NGOs that actively try to innovate methods to improve communication and provide more information to the clients. A group of NGOs in Gujarat and Maharashtra have collaboratively experimented with improving communications with the semiliterate and illiterate clients. They have developed simple booklets for health education incorporating principles of education and epidemiology, taking into account traditional beliefs of the people. They have also developed a low cost three dimensional model of uterus which can be effectively used to demonstrate IUD insertion and dispels client's fears such as the IUD will go up in the abdomen ${ }^{16}$. Gujarat Crime Prevention trust, an NGO, has developed several simple tools such as view master slides and magnetic slate to help convey correct information to the clients ${ }^{17}$. FPAI and other NGOs regularly use street plays, video shows and other interactive methods for conveying the family planning information.

NGOs also have more flexibility and some times do employ more committed and qualified staff. Better supervision may also encourage workers to provide more information. They have better training programmes and hence their workers may be more updated with information than the government workers. Of late NGOs are getting more opportunities to participate in workshops, training programmes and conferences from where they can learn innovative ways of improving their programmes. Plus they do periodic evaluations and prepare project reports etc., which help them to focus on information and communication related issues.

16 Nirog Project, Dr. Daxa Patel and Ashok Bhargav personal communication.

17 D.V. Mavalankar, Review of Managerial Aspects of FP IEC and Service Delivery Programme run by GSCPT and Supported by CEDPA, Washington, 1995. 
How much information do private practitioners give to their clients is unknown. But usual impression is that they are busy and hence hardly get time to talk to the clients. Clients going to private practitioners, especially gynaecologists, may be more educated and better off and hence may have more information to start with. Generally private practitioners are better at answering questions from their clients than the government staff.

The overall picture in Indian programme, both in public and private sector, seems to be one of scanty information to the clients and to the public. Much more efforts need to be done in this direction.

\section{Technical competence:}

Technical competence is one of the key elements of quality. Consequences of poor technical competence can mean death to the client. As pointed out by Judith Bruce ${ }^{18}$ it is hard to find studies on technical competence of staff. Most information is from anecdotes, internal reports or special small scale studies. Most family planning programmes have this implicit assumption that when it employees "qualified" staff it is assuring technical quality of the services. But this does not happen in reality due to two main reasons. One is that the qualification requirements may not include or emphasise the specific tasks that the person is suppose to be performing in the FP programme. For example MBBS doctors may not have done sterilization, MTP or even IUD insertion. Unless they are retrained he cannot be assumed to provide good technical quality of services. In fact, in many PHCs doctors do not provide clinical contraceptives as they do not have the required skills. Secondly, declining standards of training may mean that "qualified" person may not be necessarily capable.

18 Judith Bruce: as cited before. 
On the other hand some aspects of the technical quality may be poor not because the staff lacks technical competence but because they lack the equipment, the time or simply they do not bother to follow the norms and management is not willing/able to do any thing about it. For example our observations during the laparoscopic sterilization camps in three PHCs in 1994 show that the levels of asepsis in operation theatres is very poor. Surgeons do not change gloves after each operation. The sterilization of instrument used in the operation including the trochar and cannula are very inadequate. The general infrastructure of the operation theatre is very much lacking. Emergency medications and oxygen are not readily available. And this is all in spite of the fact that the operations are preformed by qualified obstetrician and MBBS doctors and helped by qualified nurses ${ }^{19}$. Similar observations were made about the sterilization camps in mid and late eighties by Dr. Rohit Bhatt with vivid slides to support the arguments at a recent meeting ${ }^{20}$. Even worst conditions were reported in camps in a PHC in Bihar $^{21}$. Unfortunately things at the camps have not improved much even if the number of operations done at the camp have come down from hundreds to dozens. Graphical images of such camps are presented by other observers ${ }^{22}$. Fortunately, Tamil Nadu has almost abolished the laparoscopic camp approach and hence quality of care there may be some what better.

The ICMR study on quality of the Family welfare programmes, which observed 273 camps in 19 states reported "preoperative screening for anaemia, hypertension and diabetes was not carried out on routine basis", "The operative procedure was never deferred or refused to a potential acceptor even when a physical condition warranted so", "in about $40 \%$ of subjects, the equipments and/or instruments used were either not sterilized at all or improperly

19 Dr. Dileep V. Mavalankar and Bharati Sharma. Quality of Care in Sterilization Camps in Gujarat, paper presented at the Quality of Care Workshop, organized by the Population Council at Bangalore, May 24-26, 1995.

20 Bhatt Rohit. Presentation made of quality of sterilization camps. At seminar on "Quality of care in health and family welfare" Gujarat Institute of Development Research, April 1994 Ahmedabad.

21 Dr. S. Parveen, Quality of Services in Indian Family Welfare Programme, A National Workshop sponsored by the Population Council, Ford Foundation \& USAID, Bangalore, May 24-26, 1995.

22 Small Family Happy Family. Ch 11 in. Elizabeth Bumiller. May you be the mother of a hundred sons: A journey among the women of India. Penguin Books. P. 257-81. 
sterilised". In spite of these observations, surprisingly the study found the "In general, facilities at camps site were satisfactory". Even though this study was done more than six years ago, the technical quality of care may not be very different now. Unfortunately this study did not observe the technical quality of IUD insertions. Our observations in urban clinics in Ahmedabad show that proper asepsis is not maintained while inserting IUDs and screening of cases is also haphazard if at all done. Several important clinical steps are missing while inserting IUDs. If the condition is such in urban clinic setting where doctor is inserting IUD what would it be like in a rural home where many IUDs are inserted by ANMs! The past experience of the debacle at the Indian IUD program in the 1960s is a clear indicator of what can happen with bad quality of care in a programme setting ${ }^{23}$. The current high discontinuation of IUDs inserted is an indication of poor case selection, poor technique and inadequate counselling all of which form part of technical quality of care. As IUD performance is measured by acceptance rather than continuation, the problems of quality go unnoticed.

23 Soni Veena. Thirty years of Indian Family Planning programme: Past performance, Future Prospects. International Family Planning Perspectives. Vol.9(2). June 1983. P. 35-44. 
One of the reasons that technical quality of care is poor, is that there are no protocols, manuals or guidelines, and when they are there, they are not followed. In PHCs one never finds such technical guidelines. Most work is done as per the tradition of that centre and depends on the doctor in charge. An occasional committed doctor can improve the quality of care tremendously in spite of all the constraints faced by the government set up. For example we have evidence of near excellent technical quality of care in one PHC in south Gujarat which was primarily due to very good doctor who took personal interest to improve the quality through meticulous work and supervision. And good quality service would move with this doctor where ever he went ${ }^{24}$. Fortunately, recently government of India has prepared Quality Assurance Manual and Infection Control Guidelines which hopefully be implemented and help in improving technical quality of care ${ }^{25}$. Government of India has with help from UNFPA and AVSC has set up centres for excellence in sterilization and micro-surgery with a view to improve the technical quality of care. The central government has also set up a "Expert committee on Technical matters" in sept 1990. Most of its work seems to be directed to fixing specifications for equipments and supplies and introduction of new contraceptive rather than improving technical quality at field level ${ }^{26}$. Purchase of substandard equipment, supplies and drugs is also another impediment to quality of care.

24 Hansot PHC case study. Prepared by Dr. D. V. Mavalankar \& J. Capoor for workshop on Innovations in Reproductive Health. IIM Ahmedabad. Sept. 1993.

25 Quality Assurance: A Manual for the government of India Family Welfare programme. Draft. 1. Jan. 1991.

Hospital-acquired infections: guidelines for control. Ministry of health and family welfare, Govt. of India. New Delhi. 1992.

26 Annual report 1993-4. Ministry of health and family welfare. Government of India, New Delhi. P. 21-4. 


\section{The NGO Sector:}

Technical quality of care in NGO sector provides a varied picture. There are organizations that provide excellent quality of care and there are other who need substantial improvement. Higher technical quality of care is reflected in adherence to strict criteria for eligibility for sterilization. For example at SEWA-Rural an NGO in rural Gujarat, they do not hesitate to refuse sterilization if the client does not fulfil the minimum criteria. They also do not do operations in "camp" situations. All operations are done at the base hospital so are IUD insertions. Such meticulous quality consciousness has helped them get more clients for sterilization over the years. But the "punishing quality" (as Judith Bruce calls it) of IUD insertion in this organization has restricted its access only to the villages near the hospital ${ }^{27}$. Under NGO management it is generally easier to assure minimum quality of services as the staff can be disciplined much easily than the government. There is flexibility of resources and some times more resources are available to improve quality of services. NGO projects may have better training and periodic evaluation components that encourage improvement of quality. For example the Family Planning Association of India (FPAI) which runs several clinics has their own training centre, their own guidelines for service delivery and they have been doing periodic evaluations of the quality of care provided by their branches, which is called "medical audit". They also have external agencies to evaluate their projects. Several other programmes offer quite good technical quality of care ${ }^{28}$. My sense is that many NGOs provide better technical quality of care due to higher level of commitment, more qualified doctors, smaller area of operations and direct responsibility and accountability. Only few like FPAI have systematic programme to assess and improve quality of care. Similarly Pariwar Seva Sansthan also has specific focus on quality of services and has periodic system of quality review.

Technical quality of care provided by private practitioners varies a lot. But generally should be superior as they can not afford to have clients with complications. Secondly they charge money and there is some competition which may help improve the quality of care. But because they are into money making they may cut corners to save on expense and in the process compromise on quality. For example, routinely the staff employed by the private doctors are unqualified and underpaid. But usually they are trained on the job and well supervised which may compensate for low level of formal training. Perception of the client about the quality of care at the private clinic may be better due to the fact that private clinics will try to put up a better "show" to impress the clients in various ways and in general people have the feeling that they are getting better quality when they pay as compared to services offer to them free.

Overall the technical quality varies a lot and needs improvement across the board especially in public programmes. Currently there is no effective system to ensure technical quality of care.

27 Renu Khanna, N. R. Mehta, Anil Bhatt. Voluntary efforts in community health. Review of the Community Health Project of SEWA-Rural. Aug. 1991. PP. 112-117.

28 For example, Vadu project of KEM hospital research society Pune, Maharashtra, Tribhuvandas Foundation in Anand, Gujarat. Tata Steel's Family Welfare Project in Jamshedpur, Bihar. 


\section{Interpersonal Relations:}

This dimension of the quality is difficult to measure but is crucial to the success of the programme. Clients have to develop faith and confidence in the services, then only they will come for such a personal matter as family planning. The counselling component of the FP program is closely related to creation of confidence and faith in the PHC system.

In the government set up developing interpersonal relationship with the clients is not given importance. Some of the structural and organizational processes hamper development of this element into the programme. For example usually the ANMs and the doctors are from outside the area they are serving due to the educational qualifications and recruitment criteria. Secondly, the policy of transfers may disrupt the rapport that may have developed with the community. For example, recent policy of Gujarat government of transferring all government employees who have been in one place for more than five years will be detrimental to the development of good interpersonal relationship and rapport with the community. Thirdly interpersonal relationship is not given any place in basic in-service training curricula of the ANM or the doctors. Fourthly, in Indian society and the bureaucracy which are so much conscious of class and caste hierarchy, it is difficult to expect that a government agent (who is deemed to be working on behalf of the president of the country) will develop empathy or close interpersonal relationship with the poor, the illiterate and backward. Unfortunately there are few studies of worker client interactions in the PHC set up. But one can judge indirectly what must be happening from the level of client satisfaction with workers and reported perceptions of the community members about the FP and health facilities. To build rapport repeated visits are required and the content of the interaction is also important.

Recent study from Bihar showed that only $34 \%$ of the families were visited by the ANM in last three months, and another $13 \%$ of the families visited the health centre or the health worker in the same time. Of the women who reported visit from the PHC staff $41 \%$ felt that the visit was very brief, and $22 \%$ were not satisfied at all, but three fourths of the women reported that they would feel comfortable with a revisit ${ }^{29}$. Our observations from north Gujarat and urban areas of Ahmedabad also indicate that the home visiting pattern need systematization and that the workers need to spend more time with the clients. The women in these areas were quite keen to receive information if proper rapport was built. The worker-people interactions that we could observe during our field work indicated that the workers maintain a social and psychological distance from the clients. The dialogue is also limited to specific topics like sterilization, or immunization. But because of the pressure of the sterilization targets the workers may have to develop artificial rapport and provide special care to the potential client which wanes off after the operation is over. The distance is much more between the PHC doctor and the client. Making clients to wait, ridiculing them, not taking proper social history, not encouraging them to ask questions are all not uncommon sights at the PHCs and urban health centres we have observed. May be this happens less often for FP clients because each one is important to fulfil worker's targets.

We feel that one of the reasons that workers do not develop closer interpersonal relationship could be because their superiors i.e. medical officers also treat them in an impersonal and hierarchical way. The relationship between the PHC staff is more like a pyramid rather than

29 ME Khan et al. Quality of care in FW programme form user's perspective. as cited before. 
like a team. Secondly workers have limited flexibility and are more responsible to their boss than to the needs of the clients. They are guided by the targets and hence at times neglect the communities' needs. Somewhat more tangible aspect of the interpersonal relationship is personal dignity and privacy of the clients. In most PHCs and UFWCs these aspects are lacking. Our observations of the sterilization camps indicate that there is no thought given to privacy of women clients and their comfort or psychological status. The camp approach is geared to time efficiency of the surgeon and which means that women have to wait several hours unnecessarily. Graphic and stunning picture of such lack of interpersonal quality is depicted in the film "Something like war". Rapport with women will develop if the PHC team provides them with good follow up and other curative services for the family members. Due to lack of curative skills, supplies and monitoring, this part is neglected which undermines the confidence of the people in the government system.

Studies done more than a decade ago in the state of Uttar Pradesh by IIM, Ahmedabad team $^{30}$ and our recent observations in Gujarat show that the health workers lack the skills and the confidence to build good interpersonal relationships through effective communications. This discourages them and they then tend to avoid going to the community or will visit only selected houses where they have good rapport. Supervisors also undermine the community's confidence in the worker rather than enhancing it when they go to the field. Workers' lack of confidence also comes from lack of training and back up support. All this hinders development of good interpersonal relationship between the community and the workers.

\section{The NGO Sector:}

NGOs are better suited to develop closer interpersonal relationship with the clients. Firstly they are non-governmental and hence are closer to the communities they choose to serve. They are less bureaucratic and more flexible so more capable in responding to the need of the clients. They may take up activities other than FP and health to satisfy the more urgent need of the people and in this way develop rapport with the community members. For example, workers of Gujarat Crime Prevention Trust's community based FP project have gone out of their way to solve community's and individual client's civic and social problems - some times unrelated to FP, so as to gain acceptance and develop closer rapport with the community. The trust also provides several other services like day-care for children, adult education and family counselling centre which also helps develop closer ties with the clients ${ }^{31}$.

FP projects of the corporate sector like one of the Tata Steel or the Deepak Medical foundation have a obvious advantage as they work with the organization's employees and their families. Such a situation can help build closer rapport and good interpersonal relationships, but a lot depends on the staff and the management of the programme. Client oriented programmes are in a better position to develop rapport. Hence NGOs offering more

30 Maru R. Murthi N. Satia JK. Management interventions in established bureaucracies: Experiences in population-programm management. Ch 8. In Beyond Bureaucracy: Strategic Management of Social Development. Ed. John Ickis, Edilberto de Jesus, Rushikesh Maru. P. 155-181.

31 Case study of Gujarat Crime Prevention Trust's project on community based distribution of contraception. Indian Institute of Management, Ahmedabad. 1993 and D.V. Mavalankar, Review of Managerial Aspects of FP IEC and Service Delivery Programme run by GSCPT and supported by CEDPA, Washington, 1995. 
than one service are more likely to develop rapport with the clients. Better interpersonal relationships can be possible if the management encourages it and if the individual employees understand its importance.

Poor interpersonal relationship, lack of courtesy and concern for clients is common feature of most public services and even some private services in India. But it is felt more acutely in a personalised services such as FP. Good interpersonal relations with the clients can be built if the staff are local, can speak the same language, know the culture of the clients and are of the same gender as the clients. The problem of transcending the difference between the social status of the provider and the client is very crucial to developing good interpersonal relationships, so is good communications skills. Incorporating these things in the training and monitoring of the staff will go a long way to improve this dimension of the FP programmes.

\section{Continuity of Care and Follow Up:}

Family planning being a way of controlling fertility it has to go on during the entire reproductive life of a couple. Unfortunately due to singular focus of government FP programme on sterilization for a long time the whole government machinery dealing with FP has been used to thinking of FP as a one time activity in the life of the couples. The whole FP programme of the government is geared to getting people to accept sterilization and usually forgets about them once they have done so. Continuity and follow up are more important for spacing methods of FP. But even for sterilization some follow up is required till the surgical wound heals. This has become more important as the programme has moved from abdominal tubectomies with 7 days of hospital stay to camps of laparoscopic sterilization where women are discharged in few hours after the operation. Some follow up care is also required to help deal with other problems like back ache, leucorrhea, excessive mensural bleeding that develop after operation which people causatively associate with sterilization. These problems are not uncommon. Visaria and Visaria reported that about $30 \%$ of the acceptors of sterilization had some problems - most common were back pain and weakness ${ }^{32}$. A study by ORG in five districts of Gujarat found that $27-31 \%$ of FP acceptors reported some problem. The common ones were white discharge and excessive bleeding after tubectomy and IUD, and weakness and pains after vasectomy. What is most disturbing was their finding that $74 \%$

32 Visaria L. \& Visaria P. Quality of Family Planning Services in Gujarat State, India: An Exploratory Analysis. Ch. 7. In. Managing Quality of Care in Population Programmes. Ed. Anrudh Jain. Kumarian Press. 1992. P. 113-38. 
of the couples facing such problems could not receive any medical help ${ }^{33}$. NFHS showed that $23 \%$ of female sterilization acceptors, $19 \%$ of IUD acceptors and $20 \%$ of OP acceptors had some problems. Our qualitative data also showed that women have perceptions that menstrual cycle gets disturbed some year after sterilization and then they have to go for hysterectomy. Even though technical literature is not supporting such complications ${ }^{34}$, it is very important for the FP program to help clients deal with such problems as they arise so as to avoid developing of misconception in the community regarding FP methods.

33 Report on baseline survey in Gujarat. Vol. IV. (executive Summary) Draft report. Operations Research Group. Baroda 390007, 1992. P. 28.

34 Mini-laparotomy and Laparoscopy: Safe, Effective and Widely Used, Population Report, Series C, No.9, May 1995, pp. C-145-147. 
Surveys that have asked clients regarding follow up find a generally poor record of the government programme. The ICMR study of $1987-89$ found that $60 \%$ of the ANMs asked appropriate questions regarding complaints while following up of FP acceptors, but only a third could give appropriate treatment to those who required $\mathrm{it}^{35}$. Even though the data presented is scanty it shows that ANMs are not able to provide follow up care to the acceptors of FP services. The qualitative study by Sharif and Visaria in Gujarat reported that women often mentioned that follow up services were inadequate especially if a non-health person was the motivator for the sterilization ${ }^{36}$. A study in two districts in Gujarat showed that only $51 \%$ and $67 \%$ of the clients were followed up at home by the health staff ${ }^{37}$. Recent data from NHFS showed that only $55 \%, 65 \%$ and $62 \%$ of Pill, IUD and sterilization acceptors received any follow up ${ }^{38}$. Follow up at home for these methods was $15 \%, 15 \%$ and $30 \%$ only. Our experience shows that at least one follow up visit after sterilization is generally done and in some PHCs, doctor visits the client at home.

35 ICMR study 1991. as cited before. P. 116.

36 Sharif A., Visaria P. FP programme in Gujarat. 1991. p.53

37 Visaria L. \& Visaria P. Quality of Family Planning Services in Gujarat State, India: An Exploratory Analysis. Ch. 7. In. Managing Quality of Care in Population Programmes. Ed. Anrudh Jain. Kumarian Press. 1992. P. 113-38.

38 National Family Health Survey: India 1992-93. IIPS Bombay. P. 153. 
Follow up and continuity of care is crucial for success of spacing methods. The National FP programme has been ignoring this important issue all these years. Even today the only monitoring of spacing method use is by number of new acceptors recruited during the year. There is no systematic reporting or record of the continuation, removal or expulsions. Repeatedly survey based data have shown that service statics based estimates of IUD use are overestimates. For example 1988 National FP survey by ORG reported $1.9 \%$ couples using IUD as against 5.5\% use reported by service statistics ${ }^{39}$. A study in four districts of Gujarat during 1989 showed that the survey based CPR for temporary methods varied between 1-9\% while the service statistics based estimates for the same four districts ranged from $15-27 \%$. Various explanations are given by the researchers including high discontinuation rates - much more than that assumed by the government ${ }^{40}$. Because of the pressure to achieve the method specific acceptor targets by the year end large number of acceptors are recruited or at least reported during the last quarter or the last month. A study by the Comptroller and Auditor General of India for 1983-84 for Maharashtra reported that for that year $23-37 \%$ of IUDs were inserted during the last month (March) of the financial year. CAG also found that there were no user-wise records for the conventional contraceptive distributed ${ }^{41}$. A recent study of quality of family welfare services by International Institute for Population Sciences, Bombay in three states, Tamil Nadu, Karnataka and West Bengal, showed that eligible couple registers, one of the key record to provide continuity of care, was not properly updated in any of the 54 PHCs studied; in 5 PHCs it was "some what updated" and in the rest 49 PHCs it was "not at all updated"42. Our field observations also show that the IUD client cards are not filled in any of the 4 PHCs and 3 urban FP centres we have been studying. All this goes to show that continuity of care is a concept which has not yet taken roots in the Indian FP programme.

Fortunately there are small experimental areas within the government sector where systems are being developed to provide continuity of care. For example at the Hansot PHC in Gujarat there was an innovative system of population registers introduced in mid 1980's which were regularly updated to give month by month statistics of users, discontinuations etc. Unfortunately this system never got accepted at wider state level and the established system at Hansot is also about to break down due to non-availability of registers and no attention from the state level ${ }^{43}$. Another system involving computerised information management developed at a regional health and family welfare training centre with help from our Institute is now being implemented in five PHCs of Ahmedabad district ${ }^{44}$. Similar system is also developed for Bombay Municipal corporation's health post programme. Another system developed at HRRC

39 FP practices in India, third all India survey. ORG. as cited before.

40 Visaria P. Jain A. Visaria L. Contraceptive use and fertility in Gujarat. Gujarat Institute of Development Research, Ahmedabad \& Population Council, New York. Dec. 1992. p. 93-117.

41 Family Planning: Wages of 'Target Orientation'. Economic and Political Weekly, July 1988. P.1449-50.

42 Ravi Vermam, TK Roy, PC Saxena. Quality of Family Planning Services and Care in Selected Indian States. International Institute of Population Sciences, Bobmay. May 1994. P.52-57.

43 Hansot PHC case. IIM Ahmedabad. as cited before.

44 Nirmala Murthi, K.G. Patel. .... 
in Chandigarh based on Continuous Care Registers can help in improving continuity of care and follow up of clients. A system of Family Folders has been under experimental use in Nasik district in Maharashtra. An analysis of such experiences should be useful to guide government FP programme in improving continuity of care. Unless the obsession with method specific acceptor targets is modified into monitoring of couple protection rates the orientation to continuity of care will not come.

\section{The NGO Sector}

In the NGO sector the concept of continuity of care and follow up in some what more accepted even though not universally so. Smaller NGOs have the advantage of small number of clients to deal with and hence can maintain closer rapport which leads to better continuity of care. Again FP providers in the organised sector also have the advantage of captive populations that they serve and in general the staff remains stable in the same clinic leading to better continuity of care. But many industry based FP programmes still do not have even basic records like eligible couple registers or other recording systems which will help them maintain continuity of care ${ }^{45}$. On the other hand several NGOs such as SEWA-Rural at Jhagadia and Tribuvandas Foundation in Anand in Gujarat now have micro computer based information systems that can help in maintaining continuity of care for FP clients. NGOs also have well supervised field and village level workers that can help in follow up and can provide continuity of care. Continuity of care in private practice is only possible if the clients return, as the doctors do not have any extension type activity nor do they maintain any systematic records. When the patients have good rapport with the doctors the continuity may be better as in the old GP or family practitioner system which is unfortunately fast breaking down.

In summary, continuity of care and follow up are weak in Indian FP programme which needs immediate reorientation in this direction. The method wise acceptor targets have focused the attention of programme managers away from continuity of care.

\section{Appropriate Constellation of Services (ACS):}

This element of the framework is very contextual and hence difficult to judge. Appropriate constellation of services have to be judged in view of client's need and capability of the service providing system. Overburdening the system with too many tasks may lead to poor quality as would the non-provision of appropriate services.

The government FP programme in India, set in the context of primary health care, is ideally suited to provide the appropriate constellation of services. In theory the PHC system is supposed to provide $\mathrm{MCH}$, disease control, and treatment of minor injuries and ailments. Various levels above the primary health centre, like the $\mathrm{CHC}$, district hospital, and teaching hospitals providing referral services. The PHC system is fairly well staffed with one male and one female multipurpose worker per 5000-6000 population and a fully qualified doctor at PHC covering 30,000 population who are supposed to provide domiciliary and clinic based health

45 Corporate sector and family welfare in India. Vol. II - case studies. Ed. Bhabani Sen Gupta, Anil Guha, P. P. Talwar. Council of Indian employers. New Delhi 1990. 
care services. In theory the PHC system can provide almost all the services required by the community for reproductive health. Unfortunately the evidence of the functioning of the PHC system is not so encouraging. Here I examine the evidence about the functioning of services most closely related to FP viz., maternal health, STD control and child health.

The ICMR study on quality of care done in 1987-89 showed that out of 398 PHCs observed only $20 \%$ had satisfactorily equipped and maintained labour room, in $55 \%$ of PHCs the labour room was present but not equipped properly and in the rest there was no labour room. Out of 598 sub-centres observed, only in $24 \%$ sub-centres had facility for normal delivery. Only $25 \%$ of the PHCs had adequate facilities for medical termination of pregnancy (induced abortion). Availability of instruments critical for maternal health care like BP instrument, weighing machine, urine testing and haemoglobin measurement were available and working in most (63-83\%) PHCs. But these instruments are available and working in only $9-30 \%$ of sub-centres. Even though $71 \%$ of PHCs had safe water supply and $86 \%$ had toilets, half of the toilets were not in satisfactory condition. If women have to be internally examined, facility to void urine before examination is a prerequisite. Given these infrastructural deficiencies in the PHC system one can imagine what constellation of services the PHC system can provide. Under the new pattern PHC has only one doctor. Adding his official leaves comes to about $45-48 \%$ of days in a year. On top of this he may not be available if he has gone for meetings, camps, training or field supervision and attending courts for medicolegal cases etc. Given this situation it is not surprising that on more than $50 \%$ of days doctor may not be available in the $\mathrm{PHC}$. This is also true of other PHC staff. This also hampers development of ACS - especially emergency services.

One of the important function of the PHC is providing ANC, delivery care and post-natal care, this can be considered as a appropriate constellation of service to FP. The same ICMR study showed that only $13 \%$ of the PHCs had registered more than $80 \%$ of antenatal cases. Majority of the PHCs had registered less than $40 \%$ of pregnant women. This study observed 1044 interaction of ANM with pregnant women for antenatal care in the field. All the elements of the antenatal examination observed were mostly done improperly or not done at all. The best was examination for anaemia which was done properly in $44 \%$ and the worst was BP measurement which were done properly in only $1 \%$ cases, while breast examination was not done properly in any single case. The study also observed that even in villages with PHC more than $55 \%$ deliveries were occurring at home while in villages with sub-centre or villages without any health facility more than $80 \%$ of deliveries were taking place at home. The record of Post natal care was equally dismal ${ }^{46}$. Recent data from NFHS, Gujarat shows that the picture of maternal care has not changed much. For example, even though $70 \%$ of pregnant mothers received TT vaccination and iron-folic acid tablets, only 37\% received home visit by a health worker and 50\% got antenatal check-up from doctor or health worker. $66 \%$ percent were delivered at home of which $45 \%$ were delivered by TBAs and only $7.5 \%$ of home deliveries were done by health professionals ${ }^{47}$. At national level, the NFHS data shows that $74 \%$ of deliveries are conducted at home while only $15 \%$ are in public institutions, $75 \%$ are

46 ICMR 1991. as previously cited.

47 National Family Health Survey: Gujarat, India. 1993. Preliminary report. Population Research Centre, MS University, Baroda, Indian Institute of Health Management Research, Jaipur, International Institute for Population Sciences, Bombay. July 1993. P. 17-20. 
attended by TBA or relative. Only $62 \%$ received AN care, $54 \%$ received 2 doses TT and $51 \%$ received IFA.

Given such an inadequate level of maternal health services it would be difficult to imagine existence of other constellation of services like STD/HIV, gynaecological care etc. Our field observations also suggest that there is hardly any care available at the $\mathrm{PHC}$ or the Urban $\mathrm{FP}$ centres for STD or gynaecological problems. This is in spite of the fact that prevalence of gynaecological problems is very high and STD forms an important part of appropriate constellation of services in India, where there is large unmet need for contraception and where women wait for 6-7 years after achieving desired family size to get sterilised ${ }^{49}$. Even though the termination of unwanted pregnancies has been legalized in India since 1977 the availability of safe abortion services are limited. Guestimate of illegal abortions in India are about ten times higher than the legal MTPs done ${ }^{50}$. Recent study by CORT on MTP facilities has shown that they are highly inadequate and the training of new doctors is so slow that it can not expect to help the situation in future ${ }^{51}$.

There are many reasons why appropriate constellation of services have not developed in the government system in spite of the framework of primary health care in which the FP programme is operating. One of the important reasons, several researchers have argued, is over emphasis given to FP and sterilization within $\mathrm{PHC}^{52}$. Structurally even though bottom levels (below the district) are integrated, all structures above that level right up to the central government are bifurcated in to "health" and "Family Welfare" department and family welfare practically means sterilization programme. Excessive focus on FP/sterilization and pressure to achieve method-wise acceptor targets has hampered the growth of health services and development of appropriate constellation of services.

\section{The NGO Sector:}

In the NGO sector most programmes are developed around $\mathrm{MCH}$ and $\mathrm{PHC}$ type activities and hence they also have the framework for appropriate constellation of services. NGOs do not

48 Bang, RA et al. High prevalence of Gynaecological diseases in rural Indian women. The Lancet. 14 Jan.1989:85-88.

Prevalence of clinically detectable gynaecological morbidity in India: Results from four community based studies. Baroda Citizen's Council, Child In Need Institute, SEWA-Rural, Streehitkarini. Unpublished 1995. Luthra, UK et al. Reproductive tract infections in India: The need for comprehensive reproductive health policy and programmes. In: Reproductive tract infections: Global impact and priorities for women's reproductive Health. Ed. Germain A. et al. Plenum press. New York. P.317-42.

49 S. Iradaya Rajan, US Mishra, Mala Ramanathan. The two-child family in India: Is it realistic? International Family Planning Perspectives. Vol. 19(4) Dec, 1993. P. 125-28 \& 153.

50 Chhabara, R, Nuna S.U., Abortion in India: An overview, p.21-24.

51 Situational analysis of MTP services in Gujarat. Centre for Operations Research and Training, Baroda. 1993.

52 D. Banerjee. Family Welfare Programme Change in Socio-Cultural and Political and Administrative Analysis of Health Policies and Programmes in India in Eighties: A Critical Appraisal. Lok Prakash, New Delhi 1990, pp.133-117. 
share the excessive unifocused approach to FP that government has been implementing, hence they are more likely to develop ACS. Most of the times the NGOs enter - FP - very reluctantly and after they have established their credibility in the community by serving the urgent community needs, except in the case of FP NGOs like the FPAI. Such family planning NGOs were also fairly uni-focus for a long time. But of late such NGOs are also developing other services. For example FPAI is not working on adolescent sexual behaviour and sex education ${ }^{53}$. Pariwar Sewa Sansthan (Marie Stopes Clinic) also provides contraceptive services and other reproductive health services besides their main activity of MTP. Most corporate sector FP systems provide $\mathrm{MCH}$ care and also have in-patient care facility to treat the employees of the company. But how much synergy happens between such services and $\mathrm{FP}$ is not clear.

53 Family Planning Association of India, Annual Report 1992. 
Private practitioners offering FP services may be offering ACS as they are basically providing curative health care and FP is one of the services. But here again how much integration of various services happen actually has to be studied. The very rapid acceptance of FP provision by the practitioners of traditional and non-allopathic systems of medicine in an experimental project in UP state may be an indication of how ACS can increase acceptance of FP in an area where government services have not been very successful in increasing FP use $^{54}$. Indian Medical Association is also trying to encourage its members to provide Oral pills to their patients through a systematic training intervention with assistance from USAID. The preliminary reports of this intervention are also encouraging.

Overall the review shows that the quality of care in public and private sector is not up to the mark and lot needs to be done to improve quality in FP programme.

\section{Why is Quality Poor?}

Poor quality in government or in NGO programme is very dangerous to the client as well as to the programme. Poor quality leads to dissatisfaction, may cause physical harm, and finally under-utilization of the services and unmet need. Reasons for poor quality could be several. They can be divided in to lack of resources and poor management. Unfortunately most of the times lack of resources is cited as reason for poor quality, but in reality, management failure is a more common and more important reason.

Poor physical infrastructure, non-availability or poor quality of equipments and supplies, lack of staff etc., may hamper any well managed programme. At times policy framework will also restrict the choice of contraceptives available which could affect the quality of the programme. Management has the responsibility to ensure quality of the services. Unfortunately in India consciousness about quality in general is low and it is more so in public programmes or services. Generally public services are seen as charity by the rulers ( the government) to the poor people and hence question of quality does not arise. This sense may also be present in some NGOs. Secondly, the top managers are not aware of the poor quality that the people have to face at the tail end. Because top managers never visit or obtain services from the peripheral institutions and if they do the services are specially window-dressed to show the boss that every thing is fine. Management also does not want to know what is really happening as the blame will come on them if things are found to be poor.

54 Indra P. Kambo, R.N. Gupta, A.S. Kundu, B.S. Dhillon, H.M. Saxena, and Badri N. Saxena, Use of Traditional Medical practitioners to Deliver Family Planning Services in Uttar Pradesh. Studies in Family Planning, Vol.25, Number 1, Jan/Feb. 1994. 
The management information system is also such that it gives one an idea of quantity rather than quality. There are no set protocols for assessing quality of FP services. The only understanding of quality in the FP programme managers is that of demographic quality i.e. average parity of acceptors used to assess whether sterilization is accepted by low parity women. The clients have no systematic mechanism to protest against the poor quality of public services in general and FP in particular. There is a feeling that for clients coming from poor strata of the society and with high unmet need, any quality of service is better than no service. Also when choices are limited quality does not matter. Again most government infrastructure, however bad, is better than houses of and living conditions of, may be, half the clients and hence they may perceive the quality as acceptable. But even the poor and illiterate can differentiate between good quality and poor quality of services as shown by the IIPS study of quality in 3 states referred earlier. In that study the quality of PHC infrastructure ratings do not vary with literacy or with caste of the respondent. Poor and good PHCs are rated so by all sub-groups of clients ${ }^{55}$. Another reason why quality remains poor is because cost of improving quality can be easily measured and has to be put up first. But cost (damage) of poor quality can not be easily assessed and it accumulates over time. The current systems of budgeting and accounting does not take these costs of poor quality into account.

\section{What can be done to improve quality of FP Programme:}

Given the status of quality of care in Governmental and NGO sectors it is clear that action to improve needs to be taken at various levels and in multiple directions. Based on the review what action needs to be taken are suggested here. The process to be followed and the tools and techniques for measuring and improving quality of care are well described in recent papers by Karen Hardee and Brian Gould ${ }^{56}$ as well as $\mathrm{J} \mathrm{K}$ Satia ${ }^{57}$ and in a recent issue of The Family Planning Manager ${ }^{58}$. Hence I will not be describing that here. Following the Bruce Framework, I have taken each of the six elements and given recommendations for their improvement.

\section{Choice of Methods:}

The limited choice of methods in Indian programme is mainly due to method specific acceptor targets and heavy emphasis on sterilization. Hence to improve the choice such targeting system and pressure to achieve them should be abolished not only nominally as is currently done by renaming targets as "Expected Level of Performance", but in spirit and action. The

55 Ravi Verma et al. as cited earlier. P.48-50.

56 Karen Hardee \& Brian Gould. A process for service quality improvement in Family Planning. Family Health International, Durham, North Carolina. Dec. 1992.

57 J K Satia. Improving quality of family planning programmes. ICOMP, Kuala Lampur, Malaysia. 1993. Unpublished.

58 The Family Planning Manager Jan-Feb. 1993, Vol.II, Num.1. Management Science for Health, Boston. 
recent World Bank review of Indian FP Programme has also suggested the same ${ }^{59}$. Fortunately GOI has started to move into this direction by freeing one or two districts from each state from the target driven monitoring system following lead from Tamil $\mathrm{Nadu}^{60}$. Unfortunately the alternatives to the current system are not clear. Several alternative systems suggested by experts ${ }^{61}$ should be tried out on experimental basis first and then suitable

59 The World Bank. India's family welfare programme: Towards a reproductive health and child health approach. June. 23. 1995. Population and Human resources division. south Asia country department II. Report no. 14644-IN.

60 The World Bank, India's Family Welfare Program: Toward a Reproductive and Child Health Approach, June 23, 1995. Report No.14644-IN.

$61 \mathrm{~K}$ Shrinivasan and Moye W. Freymann. Need for a reorientation of family planning programme strategies in developing countries: A case for birth based approach. Himalaya Publishing House, Bombay.

John Townsend and ME Khan. Target setting in family planning programmes: Problems and Potential Alternatives. Paper presented at the 1993 annual meeting of the Indian Association for Population Studies, held at Annamalai University, Chidambaram, Tamilnadu, Dec. 1993. The Population Council, India. 
system can be adopted. As a first step the government can at least move to CPR based targets rather than current method specific acceptor targets. A brief experiment of removing targets and replacing it by improved quality of care done by collector of North Arcot Ambedkar district in 1991-2 has shown that performance can be improved by such efforts ${ }^{62}$.

Secondly, effort should be made to see that all methods are available at all PHC and subcentres and other health institutions all year round and each method is explained and promoted equally to all clients. This will require improving of logistics and retraining of the workers along with reworking of the monitoring and incentive/reward system. Involving private health care practitioners would increase the access and choice several folds especially in the rural areas. In this direction experiments done by ICMR, the Indian Rural Medical Practitioners Association and Indian Medical association should be studied and replicated.

Thirdly, process of bringing in new technology should be balanced with ensuring proper mechanisms for safety and involvement of the communities. This may hasten the availability of new contraceptives to the people which will increase the choice. A mechanism should be set up to have regular dialogue with women's groups and other NGOs working in FP to ensure their cooperation in introduction of the newer methods. Cases pending in the supreme courts against introduction of newer contraceptives should be expedited or out of court settlement should be sought. Scientifically well worked out and less controversial methods like Natural FP methods and Lactational Amenorrhoea Method should be systematically incorporated in the National programme. Progesterone only pill which is suitable for lactating women should also be introduced so that problem of Combined Pill interfering with lactation can be solved. Such concerted efforts in all the three directions will help improve the choice of methods in the country.

\section{Information to users:}

Currently the programme has very little priority on communication to the clients and the people. IEC done through mass media is inadequate and incomplete. What needs to be done is to systematically build the interpersonal communication and counselling capability at all the peripheral levels. This has to be done through training, equipping, monitoring and emphasising communications efforts. Training will be needed at all levels and will have to be skill based with lot of supervised practice. The health teams will have to be provided appropriate and understandable materials for helping the communication process. The current process of preparing such materials will have to be altered to ensure that the materials are scientifically correct, appropriate to the audience and adequate. The monitoring system will have to be modified from the current counting of OTCs done to more meaningful assessment of communication process. New indicators will have to be prepared for this task. Frequency of HE meetings has to be increased to about 2-3 per worker per month. The doctors should

62 Ramsundaram. Presentation at a workshop on Management issues in Family Planning. At Banglore, March 1994. 
attend them to support the workers. Large OTC should be at the rate of 1 per month in each PHC. All this is a difficult and long process which will take 3-5 years time. Involvement of NGOs and community groups should be planned. Strategic alliances with other social services programmes such as ICDS, Adult literacy, Mahila Samakhya, DWACRA etc. may make this task easier. Inputs from agencies and NGOs working in communications and research institutions should be sought. Concerted efforts in this direction will help generate future demand and improve client satisfaction leading to better continuation of methods.

\section{Technical competence of the providers:}

This is a tough task as it involves several level of providers. Fortunately work has already begun in this direction as noted earlier in form of preparation of manuals and guidelines. The key task seems to be implementation of the protocols in the whole country to ensure minimum level of technical quality. Professionals will respond positively to such efforts if approached properly. The infrastructural and supply problems that hamper technical quality have to be solved first. The unnecessary pressure to achieve targets has to be abolished and the work has to be phased out all through out the year so as to avoid too many operations in the last quarter when the quality generally deteriorates. Proper training of the surgeons, nursers and other staff can not be over emphasised. Training should also include when not to operate or insert IUD - if the client is unfit or if the infrastructure/equipments are not proper. Technical quality standards have to be developed and communicated down the line. Tools like Standing Orders, Protocols and Standard Operating Procedures (SOP) and recording systems have to be developed to ensure implementation of the standards. Pre-service training and inservice training on regular basis should be done to keep up the standards of quality. Each step of service delivery has to be defined, standardised put in a manual and practised as a drill to ensure its internalization. Periodic checking and supervision of the technical quality of the programme by external observers/experts, may be a medical collage team, and systematic solution of the problems or barrier to quality will help improve it. The state level and district level technical/quality improvement committees should be formed or reactivated if they exist already. Regular collection and compilation of statistics on side effects, complication and deaths, with special confidential inquiry in to each death and all severe complications will help point out the lacuna for improvement. Each year a technical quality meeting should be held at state level to review mortality and morbidity data and, discuss problems and their solutions. International agencies should support and help monitor technical quality of the programme.

\section{Interpersonal relations:}

This is a difficult area to improve in the government set-up unless the work culture changes. This area, unlike technical competence is less amenable to training intervention. It will require different type of intervention, along with change in the way employees themselves are dealt with by their superiors. Interpersonal relationships can be build only if the pressure on targets goes so that the worker can see clients as persons needing service rather than as mere objects to meet their targets with. A client oriented approach rather than target orientation will lay the foundation for moving in this direction. To develop good interpersonal relationships the organization has to build courtesy, and empathy into the relationships with the clients. But in many areas where contact with the clients is very less and irregular the first step should be to systematize the worker-client/community contact. And only then improvement at interpersonal relations will have impact. This will require intensive Organizational Behaviour (OB) Labs type training. Methods like role play will be very useful. Workers's habits change 
very slowly hence a long term strategy which has monitoring and rewards for better interpersonal quality will have to be worked out. Periodic surveys, and qualitative studies of interpersonal dimension of the quality of services in local areas should be done and followed by steps to deal with lacunae and problems found.

\section{Continuity and Follow up:}

Continuity and follow up as well as interpersonal relations are closely linked. Developing one will help development of the other and one is required for the other to happen. First thing to do is to move from the yearly acceptor targets which are discouraging continuity to CPR based targets, which will mean that the attention has to be paid to continuation especially for spacing methods. Follow up is an integral part of good technical quality of care and it will also help assess the technical quality of the procedures. Once the programme moves to CPR based evaluation then client-wise records will have to be maintained which will help ensure continuity and follow up. Specific protocols for follow up and continuity of care will have to developed and adherence to protocol and cohort continuation rates etc will have to be monitored to assess progress to wards better continuity of care and follow up. Encouraging switching in case of problem and proper recording of problems as well as switching will help improve the quality of care. A life cycle approach to contraception with proper counselling at each stage of the couple's life will have to be developed for the concept of continuity to be internalised in the programme. Regular contact with the clients is an key element of continuity of care. Systematization of house visiting and clinic activities will have to be done to achieve this. Continuity based measures of performance will have to be worked out to encourage the workers to focus on this issue. Redesign of MIS has to be done to ensure ease of recording and analyzing continuity measures. Experience from experimental projects on continuity of care mentioned earlier and other such experiences around the world should serve as a guide for developing interventions in this direction.

\section{Appropriate constellation of services (ACS):}

Progress on this dimension may seem easy as there is already a programmatic framework of $\mathrm{PHC} / \mathrm{MCH}$ in most programmes which can provide the ACS. But selecting and operationalizing the appropriate services could be challenging. In this element more so than others a local context based approach will have to be adopted because needs and capabilities vary substantially with locale and organizations. No single blue print of ACS will be optimal for all areas. This will mean encouraging variations of services based on local needs and capabilities. It may be possible to divide the country in to 4-6 settings based on socioeconomic, geophysical and epidemiological situation and organizational capability - for example urban slums, average/better rural areas, backward rural areas, tribal areas, hilly, desert and semi desert area, villages and towns along main highways; and then develop a basic pattern of ACS for each of the settings. Then for each local area according to the settings the ACS package could be fashioned to suite the specifics of that place. For example in a tribal area where access is difficult and STDs are common, a decentralized approach to STD control may be appropriate service to add to the FP package with more emphasis on condom use rather than IUD. Developing such ACS will require information on the local epidemiology of diseases, data on health providers and health seeking behaviour and geography of the area. Decentralization will be the watch ward for any such effort. This will mean that the role of the central government may change from providing programme blue 
prints and earmarked money to provider of technical assistance and flexible money to states and local area to develop their own variations in the programme structure and processes.

To summarise, action will be required at policy level, programme design level, programme implementation level and monitoring level to improve quality in the family planning sector. The salient action points are.

1) Policy change to emphasise quality of care and client orientation.

2) Reworking of the target orientated programme implementation.

3) Developing quality standards, protocols, guidelines etc.

4) Skill based training oriented to quality of care.

5) Fixing up the infrastructure, equipments and logistics.

6) Changing work culture to reflect client orientation and worker participation.

7) Strengthening supervision, monitoring and MIS

\section{Managerial Implications of Improving Quality:}

Improving quality requires commitment from the top management to the concepts and processes of quality. It also means that management has to change a lot and take a leadership role in improving quality. Organizational environment has to change specifically to ensure orientation to the clients, focus on processes rather than targets, involve and empower employees at the lowest level and use of data to monitor and decide. To improve each dimension of quality a iterative process of Plan, Do, Check and Act (PDCA) approach is needed. The process of improvement has to be continuous, incremental and long term. As quality improves the programmes becomes complex and requires much more managerial inputs.

Given the current status of the programme the task of improving the quality may seem daunting but small beginning have already been made and the country is full of institutional resources that can help the process of quality improvement. So the way to go will be to try out quality improvement in small areas, starting with simple interventions and then scaling up and transferring that experience to other area on larger scale. When new programmes and projects are being developed, such opportunities should be grabbed to include components of quality improvement and capacity building for quality improvement at training and research organizations. Closer links of such organizations with implementing agencies will help in this journey to better quality of family planning programmes in India. The World Bank supported Reproductive and Child Health Project will provide a golden opportunity to improve quality of $\mathrm{MCH}$ services in India. 